1994-07-01

\title{
Raman Spectroscopic Study of the Formation of t-MoSi2 from Mo/Si Multilayers
}

\author{
Ming Cai \\ mingcai2000@yahoo.com \\ David D. Allred \\ allred@byu.edu
}

A. Reyes-Mena

Follow this and additional works at: https://scholarsarchive.byu.edu/facpub

Part of the Astrophysics and Astronomy Commons, and the Physics Commons

\section{Original Publication Citation}

The following article appeared in the Ming Cai, David D. Allred, and A. Reyes Mena, "Raman spectroscopic study of the formation of t-MoSi2 from Mo/Si multilayers," Journal of Vacuum Science \& Technology A 12(4), 153541 (1994). and can be found at [http://avspublications.org/ jvsta/resource/1/jvtad6/v12/i4/p1535_s1][http://dx.doi.org/1.1116/1.579351].

\section{BYU ScholarsArchive Citation}

Cai, Ming; Allred, David D.; and Reyes-Mena, A., "Raman Spectroscopic Study of the Formation of t-MoSi2 from Mo/Si Multilayers" (1994). Faculty Publications. 1171.

https://scholarsarchive.byu.edu/facpub/1171

This Peer-Reviewed Article is brought to you for free and open access by BYU ScholarsArchive. It has been accepted for inclusion in Faculty Publications by an authorized administrator of BYU ScholarsArchive. For more information, please contact ellen_amatangelo@byu.edu. 


\title{
Raman spectroscopic study of the formation of $t-\mathrm{MoSi}_{2}$ from $\mathrm{Mo} / \mathrm{Si}$ multilayers
}

M. Cai and D. D. Allred

Department of Physics and Astronomy, Brigham Young University, Provo, Utah 84602

\author{
A. Reyes-Mena ${ }^{a}$ \\ MOXTEK, Inc., Orem, Utah 84057
}

(Received 4 October 1993; accepted 11 April 1994)

\begin{abstract}
We have used Raman spectroscopy, large- and small-angle $x$-ray diffraction spectroscopy of sputter-deposited, vacuum-annealed, soft $\mathrm{x}$-ray $\mathrm{Mo} / \mathrm{Si}$ thin-film multilayers to study the physics of silicide formation. Two sets of multilayer samples with $d$-spacing 8.4 and $2.0 \mathrm{~nm}$ have been studied. Annealing at temperatures above $800^{\circ} \mathrm{C}$ causes a gradual formation of amorphous $\mathrm{MoSi}_{2}$ interfaces between the $\mathrm{Si}$ and Mo layers. The transition from amorphous to crystalline $\mathrm{MoSi} \mathrm{S}_{2}$ is abrupt. The experimental results indicate that nucleation is the dominant process for the early stage and crystallization is the dominant process after mucleation is well advanced. In the thicker multilayer, a portion of the silicon crystallizes during annealing and a strong Raman signal is observed. An advantage of Raman spectroscopy is that the Raman signal of the silicide is observed even before the presence of $\mathrm{MoSi}_{2}$ can be seen using $\mathrm{x}$-ray diffraction. This study indicates that Raman spectroscopy is an effective technique for characterizing the formation of crystalline silicides.
\end{abstract}

\section{INTRODUCTION}

The formation of silicide is important technologically both in very large-scale integration where silicides are being used as interconnect films ${ }^{1,2}$ and in producing better soft $X$-ray multilayers. In the latter case interfacial roughness and/or mixing in real Mo/Si multilayers keeps the peak reflectance from achieving the theoretical maximum of $80 \%$ which is predicted for multilayers containing atomically abrupt and smooth interfaces.

The reflectance is achieved by the interference occurring at the sharp interfaces between these layers. Generally speaking, the sharper and smoother the interfaces, the higher the reflectance which can be obtained. Techniques which can detect and quantify the intermixing at interfaces are extremely important for preparing the superior multilayers required for soft $x$-ray projection lithography, since a $10 \%$ gain in the reflectance in each mirror of the eight-mirror system contemplated for lithography could triple the light through the camera.

Small-angle $\mathrm{X}$-ray diffraction (XRD) and direct imaging by scanning transmission electron microscopy have been successful in characterizing the interfaces of soft $x$-ray multilayers but can give artificially high estimates of interfacial thickness since roughness and interdiffusion are difficult to distinguish. Raman spectroscopy (RS) has also been shown to be a useful technique for characterizing multilayers of amorphous semiconductors, such as $\mathrm{Si} / \mathrm{Ge},{ }^{3}$ and multilayers of metal/carbon, such as W/C multilayers, ${ }^{4}$ because in some cases it can directly "count" interfacial bonds.

We are the first group to apply a Raman spectroscopic technique to characterize soft $\mathrm{x}$-ray $\mathrm{Mo} / \mathrm{Si}$ multilayers. ${ }^{5}$ We have observed the presence of amorphous silicon in as-

\footnotetext{
an leave from the Programa Multidiciplinario de Materiales Avanzados, Centro de Investigación y de Estudios Avanzados del Instituto Politécnico Nacional, Unidad Saltillo, 25000 Saltillo, Coahuila, México.
}

deposited multiayers and, as reported here, its disappearance and the formation of crystalline molybdenum disilicide $\left(\mathrm{MoSi}_{2}\right)$ in annealed multilayers. The Raman spectroscopic study of commercial $\mathrm{MoSi}_{2}$ powder has also been carried out to help identify the $\mathrm{MoSi}_{2}$ peaks. Both large- and small-angle XRD measurements have been performed to aid in understanding Raman results. Scanning electron microscopy (SEM) and atomic force microscopy (AFM) measurements provide a direct picture of the surface topology evolution during annealing and are reported here for the first time.

\section{EXPERIMENT}

The molybdenum disilicide powder was purchased from Aldrich Chemical Company, Inc. The powder's average particle size is about $1 \mathrm{\mu m}$ and its manufacturer quotes the purity as $>99 \%$. This bulk material was obtained in order to provide a standard with which to compare the thin-film material.

The as-received $\mathrm{MoSi}_{2}$ powder and the as-deposited thinfilm samples were subjected to vacuum annealing, to air annealing, and the powder also to $\mathrm{KOH}$ etching. This was done to aid understanding of the observed features in Raman and XRD spectra. The vacuum annealing consisted of sealing the sample in an evacuated $\left(-1.0 \times 10^{-3} \mathrm{~Pa}\right)$ quartz tube or glass ampoule. For the sample annealed in air, the ampoule was not sealed. The furnace was stabilized at $1000^{\circ} \mathrm{C}$ and the sample was placed directly in the hot oven at the beginning of the annealing time and quenched by withdrawing the ampoule directly from the furnace at the end of the annealing time. As an alternative to annealing and to etch out the unreacted materials and impurities, some of the powder was mixed with $\mathrm{KOH}$ solution (10M $\mathrm{KOH}$ ), filtered and dried in air in a $110^{\circ} \mathrm{C}$ oven. This etching process was observed to remove most of the residue unreacted silicon.

The multilayer samples were made by de magnetron sputtering in a fixed target system. The layering was achieved by 
rotating the substrate in the system at a fixed rate over the sources. The Mo/Si multilayers were prepared for soft $\mathrm{x}$-ray mirror applications and were shown to have excellent soft $\mathrm{x}$-ray reflectance. The sputtering targets were molybdenum metal and $p$-type silicon. The sample substrates were ultrasmooth crystalline [100] silicon wafers. Here ultrasmooth means the wafers were selected for their snoothness. The period, or $d$-spacing $\Lambda$, was measured to be $8.4 \mathrm{~nm}$, asdeposited, with a nominal ratio $(\gamma)$ of $d_{\mathrm{Mo}}$ to $\left(d_{\mathrm{Si}}+d_{\mathrm{Mo}}\right)$ of 0.40 . There were 30 layer pairs deposited. The total multilayer thickness was thus about $250 \mathrm{~nm}$. The top layer was amorphous silicon, and it was twice made as thick as other layers in order to retard oxidation. From now on we refer to this set as thick multilayer samples.

Another group of $\mathrm{Mo} / \mathrm{Si}$ multilayer samples were prepared to be purposely very thin to magnify the interfacial effects. We will call them thin samples, to distinguish them from the other set described above. In this case, the sample substrates were ultrasmooth crystalline [111] silicon wafers. With [111] orientation wafers we can separate the weak silicides' XRD signals from the strong substrate signals which are around $2 \theta=30^{\circ}$. The period $\Lambda$ was measured to be 2.0 $\mathrm{nm}$, as-deposited, with a nominal $\gamma$ of 0.46 . There were 60 layer pairs deposited. The top is again the silicon protection layer. All samples were sealed in vacuum and annealed at temperatures ranging from 300 to $1000^{\circ} \mathrm{C}$.

The Raman spectra were recorded on a SPEX 1877 Triplemate spectrometer. The $514.5 \mathrm{~nm}$ line $(-400 \mathrm{~mW})$ of an argon-ion laser (LEXEL 96) was used as the excitation source in most studies. Other Ar-ion laser lines were used on occasion to confirm peak identifications. The laser beam was brought to line focus $\left(1 \times 10 \mathrm{~mm}^{2}\right)$ on the sample's surface using a cylindrical optic; the detector was a photomultiplier (EMI 7981B) used in photon-counting mode.

Both large- and small-angle XRD measurements were performed before and after annealing using a SCINTAG DMS-2000 powder diffractometer with a $\mathrm{Cu} K \alpha$ source $(\lambda$ $=0.154 \mathrm{~nm}$ ), at a power of $35 \mathrm{kV}-25 \mathrm{~mA}$. Small-angle XRD provides an accurate measurement of the average bilayer spacing of a multilayer mirror. ${ }^{6}$ A general rule is that the appearance of a large number of diffraction orders is indicative of sharp boundaries between the layers.

\section{RESULTS AND DISCUSSION}

The multilayer interfacial regions consist of a mixture of molybdenum and silicon, so, as was mentioned above, our preliminary work was a study of $\mathrm{MoSi}_{2}$ powder. Many silicides such as $\mathrm{WSi}_{2}, \mathrm{PtSi}$, and $\mathrm{TiSi}_{2}$ have been extensively studied by $\mathrm{RS},{ }^{7} 13^{2}$ but there has only been one published report on $\mathrm{MoSi}_{2}{ }^{14}$

The Raman spectra of the commercial $\mathrm{MoSi}_{2}$ powder samples are shown in Fig. 1. The raw powder (as-received) spectrum [see (a)] possesses four peaks: two small broad peaks located at 323 and $438 \mathrm{~cm}^{-1}$ (the higher frequency one is stronger), one fairly sharp peak located at $520 \mathrm{~cm}^{-1}$, and one small peak located at $822 \mathrm{~cm}^{-1}$. We conclude that the sharp peak at $520 \mathrm{~cm}^{-1}$ arises from the unreacted polycrystalline silicon in the powder. This is suggested by its position and was confirmed by two observations: first, the fact that

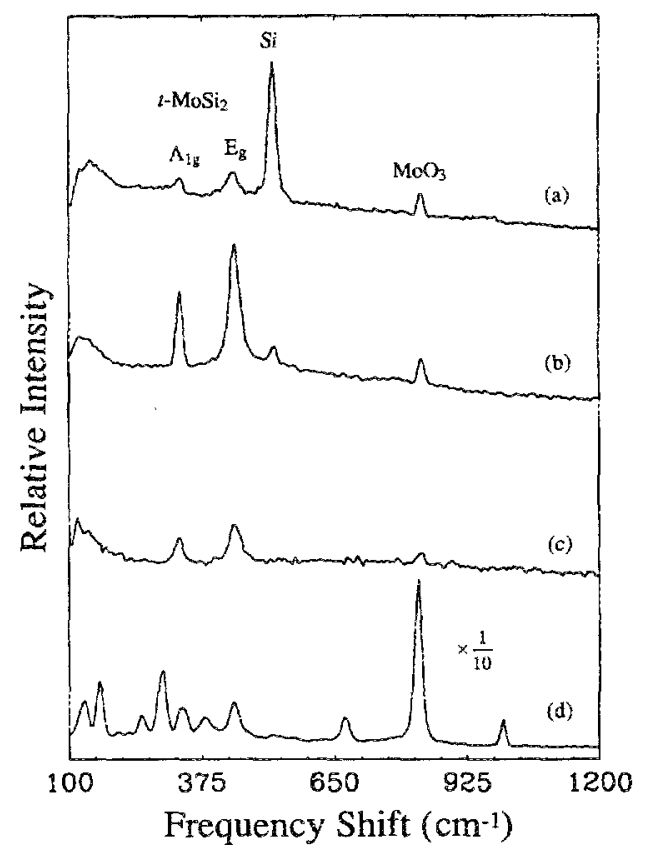

Frg. 1. Raman spectra of $\mathrm{MoSi}_{2}$ powder: (a) as-received, (b) annealed in vacuum at $1000^{\circ} \mathrm{C}$ for $1 \mathrm{~h}$, (c) etched in $10 \mathrm{M} \mathrm{KOH}$ and dried in air, and (d) annealed in air at $500^{\circ} \mathrm{C}$ for $1 \mathrm{~h}$.

the $520 \mathrm{~cm}^{-1}$ peak is lower after vacuum annealing at $1000^{\circ} \mathrm{C}$ [see (b)] and, second, the fact that it is entirely absent after etching in $\mathrm{KOH}$, which is a strong alkali that will etch crystalline silicon but will not etch $\mathrm{MoSi}_{2}$ [see (c)]. Other investigators have also reported the presence of unreacted silicon in as-received silicide powders. ${ }^{710}$ We conclude that the high-frequency peak is due to $\mathrm{MoO}_{3}$ impurity. This was suspected because of the position of the line and was confirmed by annealing in air [see (d)], as will be discussed below. The two low-frequency peaks are due to the tetragonal molybdenum disilicide $\left(t-\mathrm{MoSi}_{2}\right)$. Doland and Nemanich ${ }^{14}$ recently reported the position of $\mathrm{MoSi}_{2}$ prepared by annealing Mo on Si wafers as being 325 and $440 \mathrm{~cm}^{-1}$, which are close to our measurements of 323 and $438 \mathrm{~cm}^{-1}$. These peaks are also close to those of $\mathrm{WSi}_{2}$ at 331 and 451 $\mathrm{cm}^{-17}$, which has been studied more extensively. ${ }^{7-10}$ The vibrational mode analysis indicates two active Raman mode, $A_{1 g}$ and $E_{g}$.

After the powder sample was annealed in vacuum at $1000^{\circ} \mathrm{C}$ for one hour, we saw that the two $\mathrm{MoSi}_{2}$ peaks become sharper and stronger [curve b]. This can be interpreted as meaning that during the annealing process the original small grains of crystalline $\mathrm{MoSi}_{2}$ grew into larger grains which possess a larger Raman cross section. Analogous behavior, grain growth with concurrent sharpening, and growth of the Raman signal, has been seen in the annealing of amorphous and microcrystalline Si. Note that even after annealing the silicon peak is still observable, though smailer. We interpret this decrease in the silicon peak intensity as the partial reaction during annealing of some unreacted silicon.

To test the hypothesis that the $822 \mathrm{~cm}^{-1}$ peak is due to $\mathrm{MoO}_{3}$, we annealed the same sample again in air at $500^{\circ} \mathrm{C}$ for $1 \mathrm{~h}$. The peak became more intense (curve d). Note that 


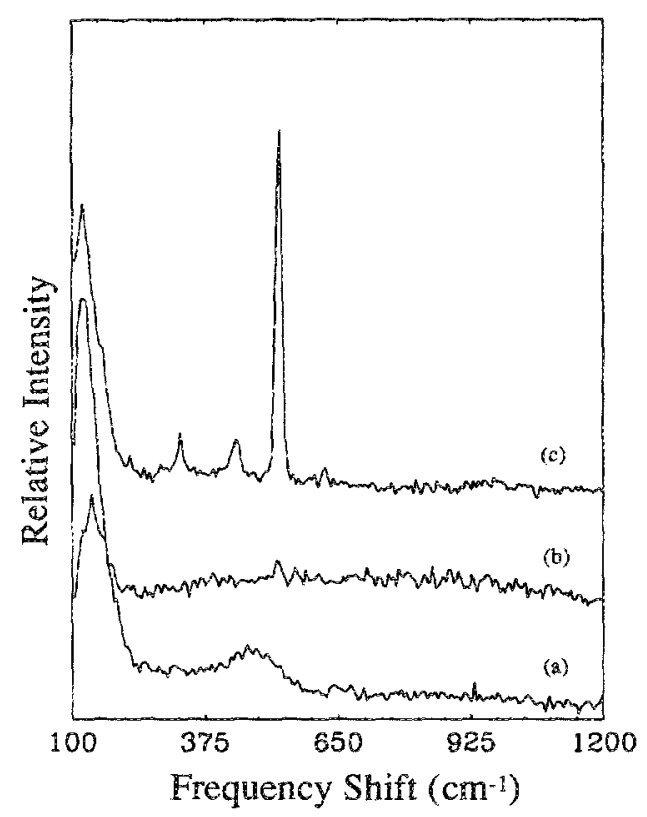

FW. 2. Raman spectra of a thick Mo/Si multilayer: (a) as-deposited, (b) annealed in vacuum at $400^{\circ} \mathrm{C}$ for $1 \mathrm{~h}$, and (c) annealed in vacuum at $1000^{\circ} \mathrm{C}$ for $1 \mathrm{~h}$.

in concert with the intensification, many other weak peaks also appear. Their positions are $996,665,438,374,329,286$, $245,218,199,159$, and $129 \mathrm{~cm}^{-1}$. Because the purpose of this experiment was only to verify that the peak at $822 \mathrm{~cm}^{-1}$ is from $\mathrm{MoO}_{3}$, the resolution was not optimized. This led to the undistinguishable peaks at 323 (from $t-\mathrm{MoSi}_{2}$ ) and 329 $\mathrm{cm}^{-1}$ (from $\mathrm{MoO}_{3}$ ). Jeziorowski reported peaks for $\mathrm{MOO}_{3}$ at $380,367,337$, and $292 \mathrm{~cm}^{-1}{ }^{15}$ He also reported another peak at $117 \mathrm{~cm}^{-1}$ which we identify as an $\mathrm{Ar}^{+}$laser plasma line. We have seen this line regardless of the sample we used. The aperture of the plasma-line climinator is not sufficiently narrow to completely eliminate plasma lines near the elastically scattered laser light. Excluding this $117 \mathrm{~cm}^{-1}$ line and the $\mathrm{MoSi}_{2}$ signal, curve d represents a perfect Raman spectrum of $\mathrm{MoO}_{3},{ }^{15-17}$ The $338 \mathrm{~cm}^{-1}$ peak has been covered by the stronger $\mathrm{MoO}_{3}$ signal. In traces a and b the oxide impurity was too small to produce a large Raman signal, and only the strongest peak of the oxide was observed. In $b$, because the powder was annealed in vacuum, there is no way for the oxide to be removed, so the oxide's signal stays approximately constant.

Raman spectra from Mo/Si thick multilayers are shown in Fig. 2. The spectrum of the as-deposited multilayer sample only gives a broad bump located approximately at $480 \mathrm{~cm}^{-1}$ [Fig. 2(a)]. We atribute this feature to amorphous silicon. ${ }^{18}$ The silicon layers of Mo/Si multilayers have previously been reported to be amorphous on the basis of transmission electron microscopy. ${ }^{19}$ Curve a provides direct evidence that these layers are amorphous and, furthermore, indicates that the amorphous silicon is highly defective since the peak is broad and weak. The metal Mo belongs to space group Im $3 \mathrm{~m}\left(\mathrm{O}_{h}^{9}\right)$ and the Mo atoms are at Wyckoff $2(\mathrm{a})$ positions. This structure does not allow any active modes and thus we see no Raman signal of Mo. We also do not see evidence of
Mo-Si bonds in the as-deposited multilayers.

One-hour, progressive temperature anneals starting from $200^{\circ} \mathrm{C}$ shows that the amorphous silicon peak disappears at about $300{ }^{\circ} \mathrm{C}$ and no other changes are seen until $1000^{\circ} \mathrm{C}$ (curve $c$ of Fig. 2). The disappearance of the Raman peak due to amorphous silicon is noteworthy since it is opposite to what is often observed with the annealing of thicker layers of room-temperature deposited, amorphous silicon. In general, annealing of amorphous silicon produces atomic reordering, giving a Raman spectrum which is more intense and shows two broad bands, one centered at about $480 \mathrm{~cm}^{-1}$ and the other one lower at $170 \mathrm{~cm}^{-1}$. The intensity of the peaks typically increases and the peaks narrow with annealing. ${ }^{18}$ The fact that his same phenomenon does not occur for the metal/silicon samples indicates that annealing may produce significantly different changes in them on an atomic level than it does in pure amorphous silicon films and silicon/ dielectric multilayers. The loss of signal indicates that the Raman cross section of the silicon layers has decreased. It may be that the material is becoming more defective-perhaps because metal atoms are diffusing into the silicon.

After this $1000^{\circ} \mathrm{C}$ annealing three peaks were seen: two peaks at 323 and $438 \mathrm{~cm}^{-1}$, respectively, which can be attributed to crystalline $\mathrm{MoSi}_{2}$, and one peak at $520 \mathrm{~cm}^{-1}$, which can be attributed to crystalline silicon.

We believe that the appearance of molybdenum silicide peaks means that extensive interdiffusion has occurred, that in this interdiffused region crystallization has begun, and that the crystallites formed are large enough to produce detectable Raman signals. The annealing process may have caused a portion of the silicon component of the multilayer to crystallize. It could be argued that the $520 \mathrm{~cm}^{-1}$ peak is due to the Si substrate coming through the film. The $250 \mathrm{~nm}$ thickness of the multilayer is, however, sufficient to block any Raman emissions from the substrate in the as-deposited film. However, interdiffusion and reaction at $1000^{\circ} \mathrm{C}$ may have made the film more transparent at the laser's $514 \mathrm{~nm}$ line. We have also inspected the sample's surface for cracks or pinholes that would give the laser probe access to the substrate, but none have been seen.

SEM analysis of as-prepared and $1000^{\circ} \mathrm{C}$ annealed multilayer surfaces shows that the $1000^{\circ} \mathrm{C}$ annealing caused grainlike structures to appear on the surface but no pinholes or cracks can be seen. In addition, the ratio of the amplitude of the $520 \mathrm{~cm}^{-1}$ peak to the $\mathrm{MoSi}_{2}$ peaks does not vary as the sample's position is changed. If it were due to pinholes, it would vary. This indicates that some crystallization of amorphous silicon dees occur.

Small-angle XRD measurement results indicate that the annealing makes the multilayer structure deteriorate. Largeangle XRD measurement result shows that after the $1000^{\circ} \mathrm{C}$ annealing, the spectrum dispiays multiple new lines instead of the broad Mo and Si peaks. The apparition of these new lines are the evidence of molybdenum silicides which have formed due to interdiffusion and interaction at multilayer interfaces. The result of the Raman spectroscopic study clearly shows the existence of $t-\mathrm{MoSi}_{2}$.

The same Raman and small-angle XRD measurements have been performed on the thin multilayer samples. The 


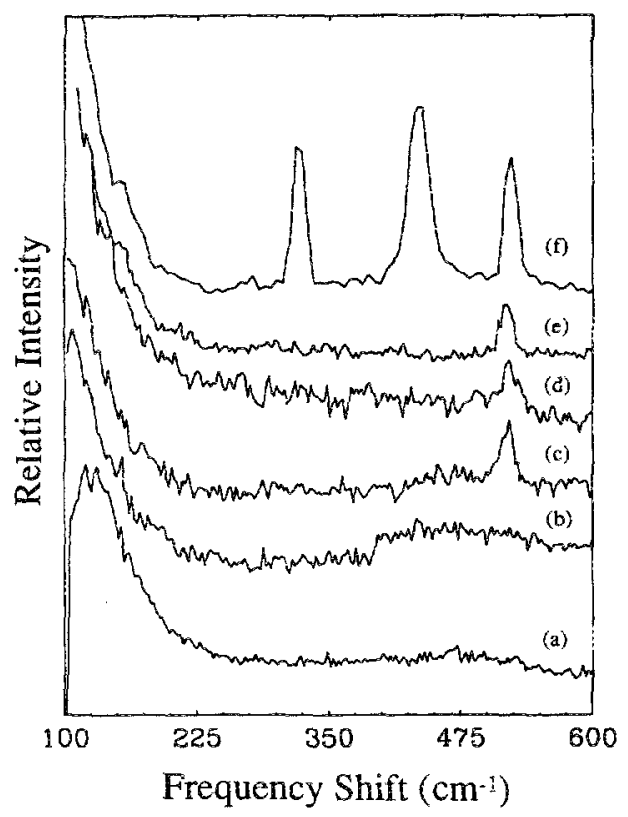

FIG. 3. Raman spectra of a thin Mo/Si multilayer: (a) as-deposited, annealed for $1 \mathrm{~h}$ at (b) 200 , (c) 400 , (d) 600 , (e) 800 , and (f) $1000^{\circ} \mathrm{C}$.

comparisons of the results between thick and thin samples provide some useful information. The Raman spectra of thin multilayer samples (Fig. 3) show similar evolution to those of the thick multilayer samples. The silicide signal from the interface did not appear until after $1000^{\circ} \mathrm{C}$ annealing. There are also some differences, however, in the Raman spectra of the thin samples (Fig. 4). These differences can be explained by the fact that the film is very thin. The first difference is

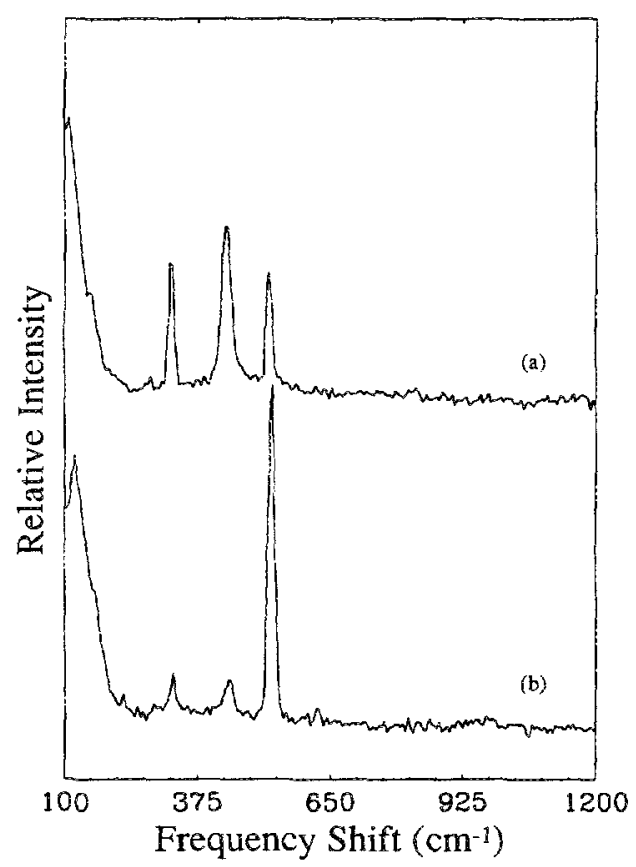

FIG. 4. Raman spectra of both thick and thin multilayer samples after $1000^{\circ} \mathrm{C}$ vacuum annealing; (a) thin sample and (b) thick sample. that a Raman signal due to crystalline silicon is observed even before annealing. We attribute this signal to the Si substrate in distinction with the thick samples-where the $\mathrm{Si}$ signal is concluded to essentially emerge entirely from the film. We presume that these films are too thin to block the substrate signal entirely. A second difference is that after annealing at $1000^{\circ} \mathrm{C}$, the silicide's signal is stronger than that of an annealed thick film. We conclude that this is because there are more interfaces for the formation of $\mathrm{MoSi}_{2}$. Third, we also note that the silicon signal in the annealed thin samples is not as strong as that with the thick samples. This supports the conclusion that this peak originated from the crystallized Si layers in the thick multilayer samples. In the thin sample, annealing has caused most of the Si layers to react to form silicide which crystallizes. If the silicon signal originated primarily from the substrate in thick samples, the thinner set, which attenuates the signal less, would produce a stronger Raman peak, but they do not. Therefore, it appears that in the case of thick samples crystallized silicon within the film is the main contributor to the Si Raman signal. We cannot completely eliminate the possibility that there is a small contribution from the substrate, however.

In contrast with the thick multilayer samples, the $1000^{\circ} \mathrm{C}$ annealing has completely destroyed the multilayer structure of the thin multilayer samples, as shown by small-angle XRD.

Several authors have reported that annealing $\mathrm{Mo} / \mathrm{Si}$ multilayers at temperatures near but under $600{ }^{\circ} \mathrm{C}$ will transform their interfaces completely into polycrystalline mixtures of $\mathrm{Mo}_{5} \mathrm{Si}_{3}$ and both the hexagonal $(h-\mathrm{MoSi})_{2}$ and tetragonal phases of $\mathrm{MoSi}_{2} \cdot{ }^{20}$ We have not seen the appearance of any molybdenum silicide until after annealing at $900^{\circ} \mathrm{C}$ or above, and only tetragonal silicide has been obtained at these temperatures. This transition temperature is probably affected by the sample deposition environment (sputtering gas pressure, etc.) and vacuum annealing. It has been reported that Mo/Si systems fabricated by different methods show different phase-transition temperatures. Further annealing studies may be required to see the hexagonal phase by Raman.

An AFM study of the annealed Mo/Si multilayers has been conducted. ${ }^{21}$ The result shows that at low annealing temperatures, the surface roughness does not display an apparent change as the annealing temperature increases. The surfaces are quite smooth until being annealed at $800^{\circ} \mathrm{C}$.

From the discussions in the last section, the $1000^{\circ} \mathrm{C}$ annealing causes not only the formation and crystallization of silicide at the interfaces but also the crystallization of the layers themselves in the film. It seems that there is more than one transformation process occurring concurrently during annealing.

We now present the Raman spectroscopic study of multilayers annealed at constant temperature, for various lengths of time.

The Raman spectra of these samples are shown in Fig. 5. As we can see, crystalline silicon is formed even after the shortest annealing time (curve b). The size of this crystalline silicon peak keeps growing as the annealing time increases (curves b-d). The silicide peaks do not appear until after annealing for $220 \mathrm{~min}$ (curve d). After the formation of the 


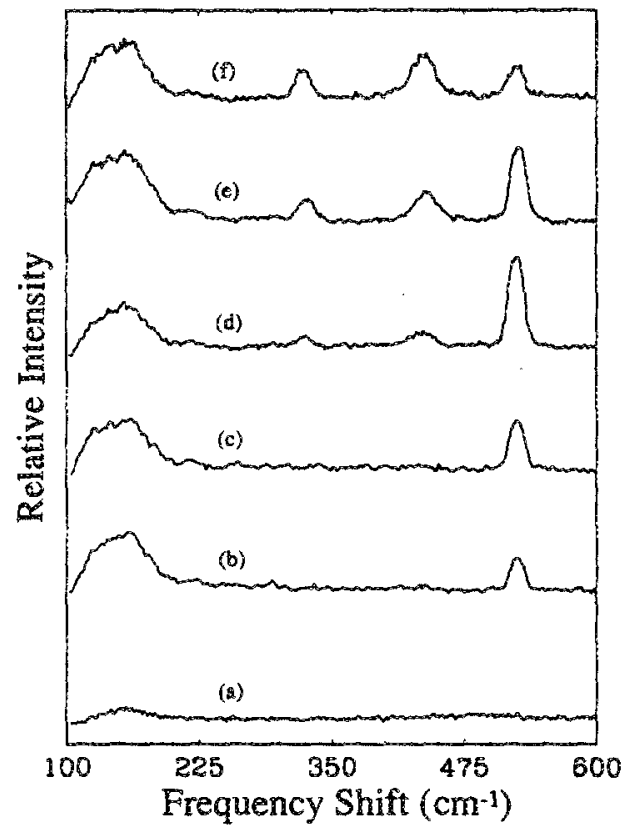

FiG. 5. Raman spectra of a thick multilayer sample: (a) as-deposited, and after $900^{\circ} \mathrm{C}$ annealed, for (b) 20 , (c) 60 , (d) 220 , (e) 615 , and (f) $2720 \mathrm{~min}$.

crystalline silicide interfaces, as the annealing time increases, the intensity of the silicide peaks increase while the peak of $c$-Si decreases (curves $\mathrm{d}-\mathrm{f}$ ).

In order to see this trend more clearly, we have graphed the change of the relative peak heights after various annealing times. The result is displayed in Fig. 6 . The peak heights of crystalline silicon are obtained by Gaussian fitting the peak at $520 \mathrm{~cm}^{-1}$ while the peak heights of silicide are obtained by Gaussian fitting the peak at $438 \mathrm{~cm}^{-1}$. These peak

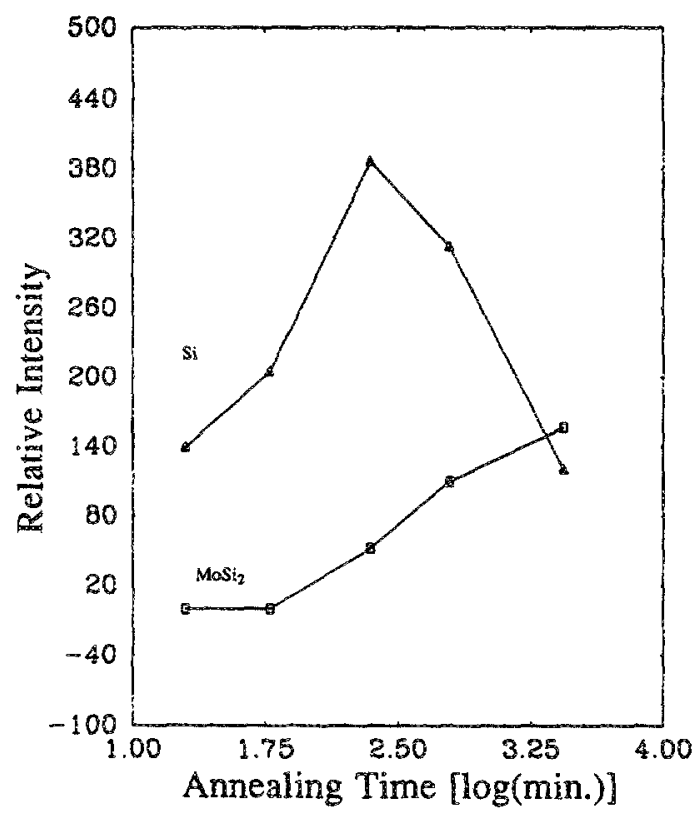

FIG. 6 . Evolution of the Raman peak heights of $\mathrm{MoSi}_{2}$ and crystalline silicon in a thick multilayer sample after various annealing times at $900^{\circ} \mathrm{C}$. heights do not represent the absolute quantities of each material because they have not been calibrated with their respective Raman scattering cross sections. Indeed, the cross section of the silicide is much smaller than that of crystalline silicon. Therefore, the amount of crystalline silicon formed during the annealing process is relatively small.

Reviewing the evolution displayed in Fig. 6, we believe that both interdiffusion and crystallization proceed simultaneously for a high annealing temperature, such as $900^{\circ} \mathrm{C}$. Because the activation energy required for Si to crystallize is lower than that for interdiffusion, the rate of Si crystallizavion is much faster than that of interdiffusion. Consequently, the silicide will be generated at the interfaces.

At the beginning of the annealing, the Si crystallization is the dominant process. Although interdiffusion also occurs at this stage, the rate is relatively low. Only a small amount of the amorphous silicon layer will be consumed by interdiffusion and reaction with Mo to form silicide. A large amount of amorphous silicon is converted to crystalline silicon by crystallization. This fact is demonstrated by the initial increase in the crystalline Si peak. Once the Si in the layers is crystallized, saturation prevails. The crystalline Si peak will stop growing even with higher temperature or longer time annealing. Instead, the continuing interdiffusion will keep consuming the crystallized Si to form more silicide, which makes the interface grow. Continuing to anneal the sample will increase the silicide signal and decrease the crystalline Si signal. This explains the decline in Si Raman intensity with long term annealing seen in Fig. 6. This will continue until either the unreacted Mo or Si is consumed.

The complete hypothesized process is illustrated in Fig. 7. Depending on the compositional (or thickness) ratio between the Mo and the Si layers, the final configuration will be different. If the ratio is less than 0.5 , there will be some crystalline silicide and some residual Mo. Instead, if the ratio is greater than 0.5 , there will be no Mo remaining. Silicide and crystalline silicon will be the products. If the ratio is exactly 0.5 , the only material formed is the silicide. Of course, in the real world the layer structure will not be preserved as shown in the figure. Crystallization proceeds along certain preferred directions according to the material. Additional studies are needed to understand the crystalline grain growth mechanism of these materials.

The rates of crystallization and interdiffusion are different at different temperatures. Therefore, generally speaking, annealing at different temperatures will exhibit different rates of interdiffusion and crystallization.

For this series of annealed samples, the small-angle XRD have been measured to see how the multilayer structure changes. From Fig. 8 we can see that the multilayer structure has substantially disappeared after $3 \mathrm{~h}$ of annealing at $900^{\circ} \mathrm{C}$. Interestingly, the corresponding Raman spectrum shows the initial formation of silicide. This suggests that the formation and crystallization of the silicide interfaces strongly affects the multilayer structure.

\section{CONCLUSIONS}

The Raman spectroscopy technique has been applied to characterize as-prepared and anneaied $\mathrm{Mo} / \mathrm{Si}$ soft $\mathrm{x}$-ray 


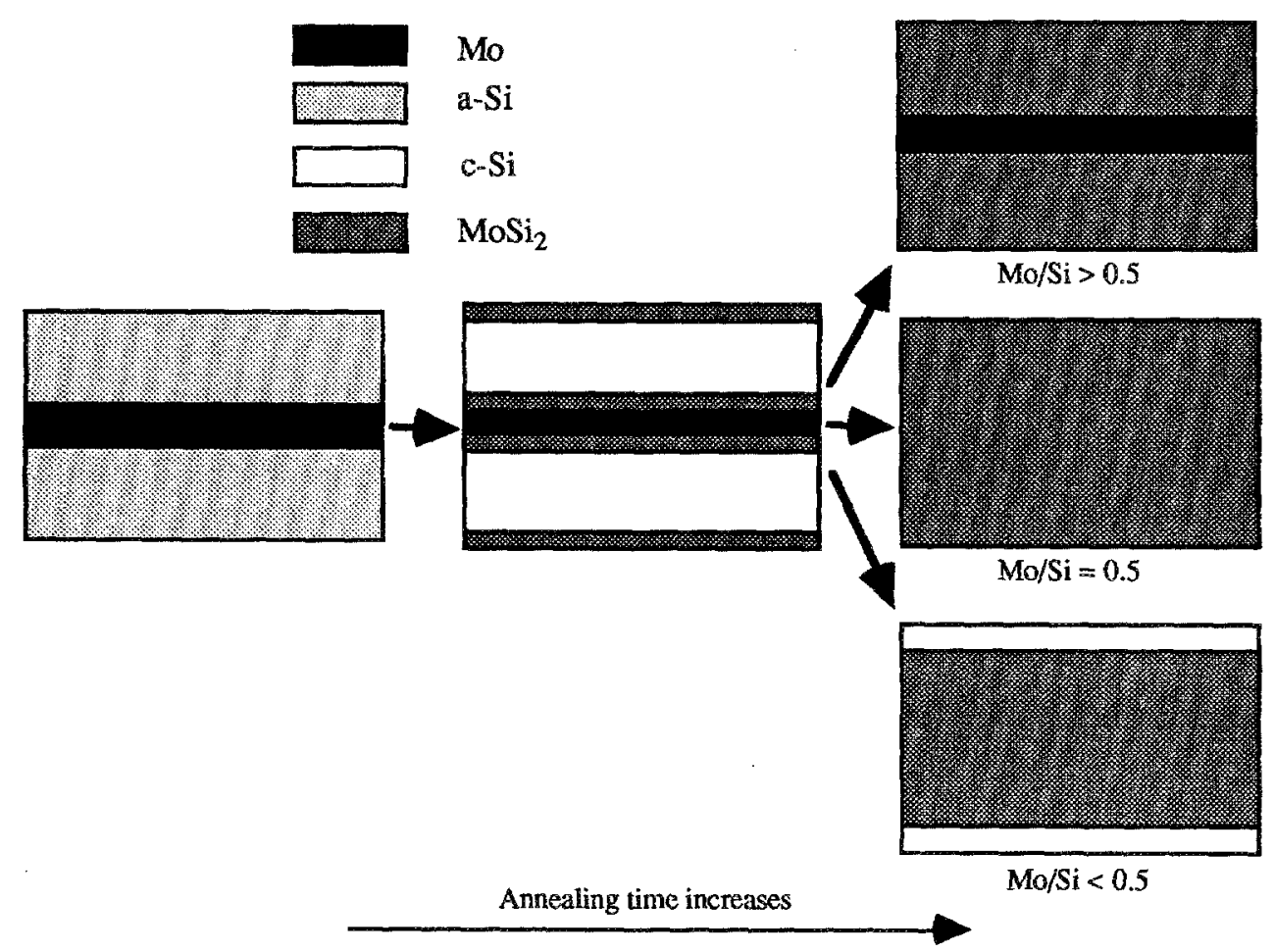

Fic. 7. Schematic of the hypothesized evolution of Mo/Si multilayers under annealing.

multilayer mirrors. The two active Raman modes of $\mathrm{MoSi}_{2}$ located at 323 and $438 \mathrm{~cm}^{-1}$ have been observed in powder $\mathrm{MoSi}_{2}$ and in annealed Mo/Si multilayers. This study shows that the multilayer thin films does not change dramatically until after high-temperature annealing. Annealing at tempera-

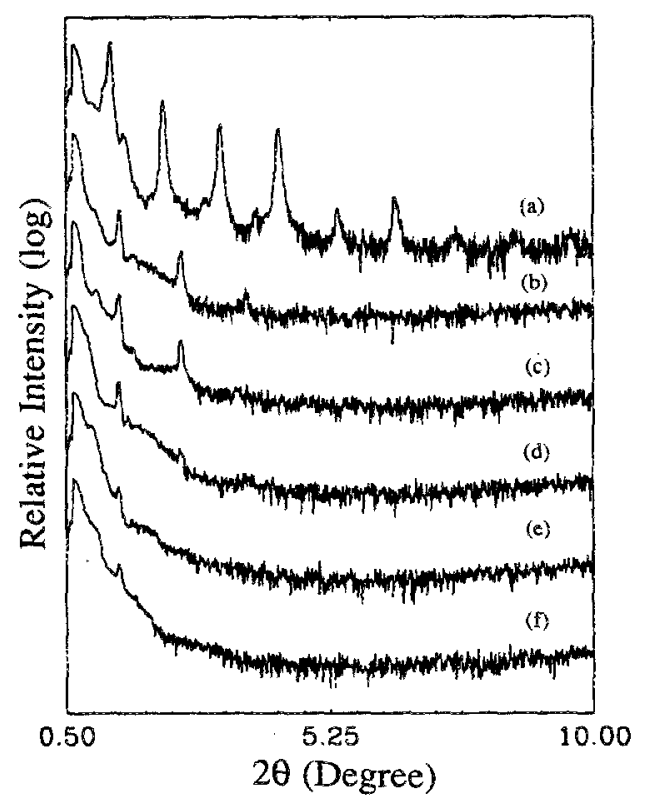

FIG. 8. Small-angle XRD data of a thick multilayer sample, (a) as-deposited and annealed at $900^{\circ} \mathrm{C}$ for (b) 20 , (c) 60 , (d) 220 , (e) 615 , and (f) $2720 \mathrm{~min}$. tures greater than $800^{\circ} \mathrm{C}$ destroys the regular, layered structure of these multilayers. Under these same conditions, crystallization is observed by RS and there is an increase in roughness both at the interfaces, as deduced by small-angle $\mathrm{XRD}$, and on the surface, as seen by AFM. At high temperatures, Si crystallization is the dominant process observed for short annealing times. With continued annealing, a growth of the crystalline $\mathrm{MoSi}_{2}$ phase and a loss of the crystalline Si phase is observed. We deduce that the silicide interfaces keep growing until one of the materials is exhausted.

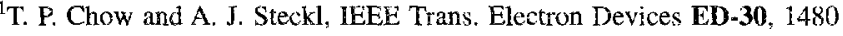
(1983).

${ }^{2}$ S. P. Murarka, Silicides for VLSI Applications (Academic, New York, 1983).

${ }^{3}$ D. D. Allred, J. Gonzalez-Hernandez, O. V. Nguyen, D. Martin, and D. Pawlik, J. Mater. Res. 1, 468 (1986).

${ }^{4}$ D. D. Alired, Q. Wang, and J. Gonzalez-Hernandez, Mater. Res. Soc. Symp. Proc. 160, 605 (1990).

${ }^{5}$ D. D. Allred, M. Cai, Q. Wang, D. M. Hatch, and A. Reyes-Mena, J. X-Ray Sci. Technol. 3, 222 (1992).

${ }^{6}$ B. L. Henke, J. Y. Uejio, H. T. Yamada, and R. E. Tackaberry, Opt. Eng. 25, 937 (1986).

${ }^{7}$ P. J. Codella, F. Adar, and Y. S. Liu, Appl. Phys. Iett. 46, 1076 (1985).

${ }^{8}$ S. Kumar, S. Dasgupta, H. E. Jackson, and J. 'T. Boyd, Appl. Phys. Lett. 50, 323 (1987).

${ }^{9}$ C. Chen, M. Cao, and W. Hua, J. Appl. Sci. 9, 258 (1991).

${ }^{10}$ M. Amiotti, E. Bellandi, A. Borghesi, A. Piaggi, G. Guizzeti, F. Nava, and G. Queirolo, Appl. Phys. A54, 181 (1992).

${ }^{11}$ D. Sun, Z. Yu, and F. Li, Acta Opt. Sinica 5, 310 (1985).

${ }^{12}$ R. J. Nemarich, M. J. Thompson, W. B. Jackson, C. C. Tsai, and B. L. Stafford, J. Vac. Sci. Technol. 1, 519 (1983).

${ }^{13}$ R. J. Nemanich, R. T. Fulks, B. L. Stafford, and H. A. Vander Plas, Appl. Phys. Lett. 46, 670 (1985). 
${ }^{14}$ C. M. Donald and R. J. Nemanich, J. Mater. Res. 5, 2854 (1990).

${ }^{15} \mathrm{H}$. Jeziorowski and H. Knözinger, J. Phys. Chem. 84, 1825 (1980),

16 A. N. Desikan, L. Huang, and S. T. Oyama, J. Phys. Chem. 95, 10050 (1991).

${ }^{17}$ L. Rodrigo, X. Marcinkowska, A. Adnot, P. C. Roberge, S. Kaliaguine, J. M. Stencel, L. E. Makovsky, and J. R. Diehl, J. Phys. Chem. 90, 2690 (1986).
${ }^{18}$ J. E. Smith, Jr., M. H. Brodsky, B. L. Crowder, and M. I. Nathan, Phys. Rev. Lett. 15, 642 (1971).

${ }^{19}$ D. G. Stearns, R. S. Rosen, and S. P. Vernon, Proc. SPIE 1547, 2 (1991).

${ }^{20}$ D. G. Steams, R. S. Rosen, and S. P. Vernon, J. Vac. Sci. Technol. A 9, 2662 (1991).

${ }^{21}$ M. Cai, Ph.D. dissertation, Brigham Young University, 1993. 